Iberian Journal of the History of Economic Thought

ISSN-e: 2386-5768

\title{
Los arbitristas agraristas de Castilla en el siglo XVII. Algunas perspectivas sobre el campesinado
}

Omar Gómez-Cornejo Aguado ${ }^{1}$

Recibido: 5 de diciembre de 2017 / Aceptado: 19 de marzo de 2018

Resumen. Los arbitristas agraristas de Castilla en el siglo XVII elaboraron proyectos para fomentar las actividades económicas del sector primario porque consideraban que la agricultura o la ganadería eran fundamentales para superar la recesión del país. Sin embargo, no solo propusieron medidas de carácter estrictamente económico, sino también otras cuestiones que afectaban al estatus y consideración que se tenía del campesino en aquel momento. Los arbitristas planificaron una reforma utópica que habría provocado un cambio profundo en el orden establecido en el Antiguo Régimen. Sus proyectos fracasaron aparentemente, pero la latencia de sus ideas perduró varios siglos.

Palabras clave: Castilla; siglo XVII; arbitristas agraristas; campesinos; mentalidad.

[en] The agrarian arbitristas of the Castilian seventeenth century. Some ideas on peasantry

Abstract: The agrarian arbitristas in Castile in $17^{\text {th }}$ century did projects to encourage the economic activities on the primary sector because they considered that agriculture and livestock were essential to overcome the recession of the country. However, they proposed not just economic measures, but also suggested some issues related to the status and consideration of the peasants in that moment. The arbitristas planned a utopian reform which would have caused a deep change in the establishment ot the Old Regime. Their plans were apparently unsuccessful, but the latency of their ideas persisted for some centuries.

Keywords: Castile; $17^{\text {th }}$ century; agrarian arbitristas; peasants; mentality.

Sumario: Introducción. 2. El arbitrismo español en el siglo XVII. 3. Arbitristas agraristas castellanos y sus perspectivas del campesinado. 4. Conclusiones. 5. Fuentes y bibliografía.

Cómo citar: Gómez-Cornejo Aguado, O. (2018) Los arbitristas agraristas de Castilla en el siglo XVII. Algunas perspectivas sobre el campesinado, en Iberian Journal of the History of Economic Thought 5(1) (2018), 17-27.

\section{Introducción}

El arbitrismo es una corriente de pensamiento económico que se dio en distintos territorios europeos. En Francia sus autores recibieron el nombre de donneurs d'avis (Mousnier 1980: 66-70); zéleux en Flandes (Echevarría 1998: 163-164); en Italia se denominaron arbitristi (Alvar 2000: 107-113) y en Austria projektenmacher (Dubet y Sabatini 2009: 868). No obs- tante, en este trabajo, debido a las limitaciones de espacio, solo se analizarán el pensamiento de algunos arbitristas castellanos en un marco cronológico también reducido: el siglo XVII, pues su desarrollo se dio durante la Edad Moderna. En efecto, el arbitrismo español surgió en la última etapa del Quinientos; en la centuria posterior adquirió su máximo auge; y continuó, aunque lánguidamente, en el período ilustrado del siglo XVIII.

\footnotetext{
Universidad de Salamanca omargca@usal.es
} 
La principal preocupación de los arbitristas era la situación de pobreza, la "declinación" en la que se estaba internando España en el Seiscientos. Por tanto, se dispusieron a analizar las posibles causas y a proponer soluciones que beneficiaran al reino, pero también a sus vasallos. De todo ello ha quedado constancia en sus trabajos, los arbitrios, una fuente histórica tremendamente interesante, ya que a través de estas obras es posible conocer la realidad y los problemas económicos de aquel siglo tal y como los interpretaban sus contemporáneos. El estudio de estas fuentes ha sido uno de los pilares fundamentales en este artículo, así como la consulta de la bibliografía existente. Entre los principales investigadores de esta cuestión destacan autores como Gutiérrez Nieto (1986), Perdices de Blas (1996; 1998) con Santos Redondo (2006) y Sánchez Molledo $(1997 ; 2005 ; 2009)$, éste último para el caso concreto del reino de Aragón.

Sería demasiado ambicioso y excedería los límites exigidos en este trabajo realizar un estudio exhaustivo de esta corriente de pensamiento económico; por ello se ha acotado el objeto de estudio al análisis de las medidas que fueron propuestas por un grupo determinado de arbitristas: los agraristas, es decir, aquellos que encontraron en las actividades económicas del hoy denominado sector primario las soluciones para que España dejara de ser "las Indias de Europa" en el siglo XVII. Sin embargo, sus programas tenían un carácter integral. Así pues, en ellos no existían solo propuestas estrictamente económicas, las cuales han sido ampliamente estudiadas, sino que también promovieron otras medidas que afectaban a la consideración social que se tenía de los trabajadores del agro. Éstas últimas son las que se han tenido en cuenta para la redacción de este artículo, pues se apenas se conservan testimonios directos sobre los agricultores y ganaderos del Seiscientos. Por tanto, se ha considerado conveniente trabajar con el relato mediatizado de varios arbitristas que fueron coetáneos. En definitiva, se pretende conocer la imagen que se tenía de los campesinos en el siglo XVII y analizar las proposiciones que los arbitristas al respecto, así como sus consecuencias y la pervivencia de sus ideas en el tiempo.

En cuanto a la estructura, primeramente, se reflexiona sobre esta corriente de pensamiento económico en España durante el Seiscientos. Posteriormente, se reseñan algunos ejemplos de arbitristas agraristas castellanos cuyas pro- puestas son sintetizadas y analizadas conjuntamente para tomar conciencia de la interpretación de la figura del campesino en la época y de la trascendencia de las propuestas que al respecto trataban de implementar los arbitristas.

\section{El arbitrismo español en el siglo XVII}

La definición que García Fernández (2002: 140) hace de los arbitristas es la siguiente:

un grupo de "economistas-políticos" que desde finales del siglo XVI se dedicaron a analizar las causas de los males públicos de la enferma sociedad española (sic.). Fueron los primeros que tuvieron conciencia de la "crisis castellana del XVII", intentando remediarla mediante multitud de proyectos. Dichos proyectos o "arbitrios" (medios extraordinarios propuestos para lograr el fin deseado) eran, en ocasiones, disparatados y, en otras, verdaderos programas de reforma. [...]. Menospreciados y criticados en su época y durante mucho tiempo, hoy son considerados "primitivos autores del pensamiento económico", reconociéndose su importancia en el análisis de la decadencia de España y la clarividencia de muchos de sus planteamientos, a la vez que testimonio de la conciencia de crisis asumida por la sociedad castellana, intentaron durante el siglo XVII mejorar la vida del campesinado y las condiciones de explotación feudales, buscando una mayor productividad del campo español, a través del estudio de las técnicas agrícolas (por eso, dentro de la literatura arbitrista, el "arbitrismo agrarista" constituyó uno de los focos más destacados).

A partir de esta definición se deduce que la heterogeneidad es el principal adjetivo que caracteriza a los arbitristas, tanto es así que esta peculiaridad lleva a Dubet a afirmar que estos "no constituían un grupo o movimiento de pensamiento" (Dubet, 2003). Sin embargo, en el Seiscientos hay un conjunto de individuos que se dispone a reflexionar sobre un problema común: la "declinación", es decir, la decadencia económica de España y producen una literatura que ha sido considerada como "el más claro antecedente del pensamiento económico de carácter científico y la base para el ulterior desarrollo de la economía política" (Avilés, Villa y Cremades 1988: 288). No obstante, por lo general, no se articulan en un colectivo cohe- 
sionado, sino que lanzan individualmente sus propuestas. Éstas recibieron en aquella época el nombre de "arbitrio" y, de hecho, existe una definición de este término en el Tesoro de la lengua castellana o española redactado por Diego de Covarrubias en 1611:

y otras veces arbitrio vale tanto como parecer que uno da; y el dia de oy se a estrechado a sinificar una cosa bien perjudicial, que es dar traças como sacar dineros y destruyr el Reino; porque de ordinario los que dan estos arbitrios son gente perdida. Verdad es que a estos tales pocas vezes se les da oydos, porque como ha de pasar el arbitrio por hombres de ciencia y conciencia, se los rechaçan, y entre otros males que hacen es acobardar a los que podrían darlos, por el mal nombre que han puesto a este género de suplir necesidades y remediar faltas.

Así pues, se evidencia que en el siglo XVII se tiene plena conciencia de lo que supone un arbitrio. Es cierto que Covarrubias tiene una interpretación particular al respecto, explícitamente peyorativa, y no será el único. Sin embargo, su definición resulta muy valiosa, pues da cuenta de la existencia de una serie de individuos que tratan de "suplir necesidades y remediar faltas" que adolecen al reino español a través de sus propuestas, las cuales podían ser inverosímiles o racionales. Por tanto, sí que se puede identificar un grupo de individuos que comparte un mismo punto de reflexión, el declive económico de España y recurren a un mismo medio para plasmar sus ideas y propuestas: el arbitrio. Son, tal vez, criterios muy amplios y generales para establecer una taxonomía de los arbitristas. Sin embargo, son los únicos que garantizan no correr el riesgo de excluir de esta corriente de pensamiento a susceptibles autores ni restringir su nómina improcedentemente.

En cuanto a la consideración que se tenía de los arbitristas en el siglo XVII, ya se ha señalado la opinión peyorativa que Covarrubias tenía al respecto. Este mismo parecer era compartido por otros intelectuales del Siglo de Oro español (Vilar 1973) tales como Cervantes (Perdices y Reeder 2006: 35-76) o Quevedo (Urí 1998: 143-169). Todos ellos denostaban a estos particulares investigadores de la situación económica española, pues los consideraban estultos, arribistas y oportunistas. Una de las razones que puede justificar esta actitud es el relativo interés personal de los arbitristas.
Estos aspiraban a que sus propuestas fueran implementadas, pues si éstas resultaban exitosas podían ser recompensados con un 5\% de los beneficios netos del arbitrio (Dubet 2003).

\section{Arbitristas agraristas castellanos y sus perspectivas del campesinado}

Gutiérrez Nieto (1986: 237), atendiendo al contenido de los arbitrios, realizó una clasificación: arbitrismo fiscal y financiero; político; social; técnico; y económico. A esta última categoría pertenecen los arbitristas agraristas, objeto de estudio en esta comunicación. Pues, estos focalizaron su atención en el análisis de las potencialidades que presentaban las actividades económicas del sector primario, fundamentalmente la agricultura o la ganadería, para resolver la decadencia española y lanzaron propuestas en este sentido. Junto a medidas de carácter meramente económico defendieron otras que propugnaba un cambio en la mentalidad y en la consideración social de aquéllos que se dedicaban a estas tareas.

Gaspar Gutiérrez de los Ríos (c.15681606), cuya biografía ha sido ampliamente estudiada por Cruz Yábar (1996; 1997), fue un arbitrista del siglo XVII que defendía la agricultura como el principal sector económico que se debía fomentar para la recuperación de España. En este sentido, destaca sobremanera su propuesta, pues en ella identificó la principal causa que provocaba el rechazo de los españoles a la hora de trabajar en el campo. Para este arbitrista el principal óbice era la convención social que existía en torno a las tareas agrarias, ya que éstas no eran consideradas como un arte liberal sino servil:

para que la agricultura (en quien entra también la pastoricia y crianza) tenga este privilegio [de ser considerada como arte liberal], según los antiguos de que no se pueda decir arte servil, ni juntarse con las mecánicas, aunque en su ejercicio trabaje más el cuerpo que el entendimiento, y no se gane por ella el nombre que por las otras liberales. Lo cual hago de industria movido de verla tan abatida y olvidada de estos reinos, para que volviendo por su honra y mostrando cuán liberal y digna de todos estados es por nobles que sean, fuera de la mucha utilidad y provecho que de ella se sigue generalmente a la república, y a todos en particular, dejando otros ejercicios que tanto se usan, indignos de hombres 
gentiles, cuanto más de los que son cristianos, nos animemos sobre porfía a amarla, honrarla y ejercitarla. (1600: 227-228)

Por tanto, Gutiérrez de los Ríos proyectaba un cambio de mentalidad respecto al campesino y trataba de dignificar este oficio, asimilándolo a uno liberal, tal y como dejó de manifiesto en el título de su arbitrio: Noticia general para la estimación de las artes y de la manera en que se conocen las liberales de las que son mecánicas y serviles: con una exhortación a la honra de la virtud y del trabajo contra los ociosos y otras particulares para las personas de todos estados ${ }^{2}$. Efectivamente, en el libro cuarto de esta obra (1600: 230-249) adujo las principales razones por las que el trabajo del labrador debía ser considerado como un arte liberal: "por la nobleza de su granjería"; "porque produce grandes efectos de virtud en el ánimo y hay en ella mayor contemplación que en las mecánicas" y "porque es hermana del arte militar". Mediante estas razones, Gutiérrez de los Ríos pretendía acabar con el estigma que el pensamiento de la época había impuesto al oficio de agricultor. Además, no solo tenía en cuenta la actividad que realizaba el campesino, sino que también exploró la personalidad del mismo y halló excelentes cualidades, de modo que lo presentaba como un modelo de virtudes:

¿Hay gente más amiga de sus reyes que los labradores? ¿Hay gente más enemiga de novedades que ellos? ¿Hay gente más contraria de tiranos y traidores? Pregunto: ¿Qué gente hay de mayor paciencia? ¿Qué gente hay más abstinente ni de más modestia en sus comidas? No consiente la agricultura vicios ni ateos, poltrones ni epicúreos, como andan en nuestra España (mal pecado) por las ciudades en figura de cristianos. (1600: 238).

Asimismo, frente a la relevancia moral y económica del campesino y su trabajo, este arbitrista criticaba severamente a los ociosos, es decir, a aquéllos que rechazaban desempeñar cualquier oficio, en especial el considerado como mecánico, pues, aspiraban a medrar y aquella actividad era incompatible con el ascenso social en aquella época:
A tanto pues ha llegado el menosprecio del trabajo y descomedimiento de la ociosidad, que ya algunos hombres de bajos principios les parece que para ganar nobleza e hidalguía sus hijos, importa mucho que sean ociosos de que han resultado y resultan los grandes daños que vemos. (1600: 256)

El interés de Gutiérrez de los Ríos por hacer atractivo el trabajo en el agro para la sociedad de su tiempo va a ser compartido por otro arbitrista: Pedro de Valencia (1555-1620). Éste, en su obra Discurso sobre el acrecentamiento de la labor de la tierra, ${ }^{3}$ propuso que la agricultura fuera tenida como una actividad propia de la baja nobleza (hidalgos) y como una ocupación obligatoria para ocupar cargos públicos en el ámbito local.

se prohíba a los hidalgos de España usar otro oficio que de soldados o labradores. Tendremos honrados labradores y, luego, todo el oficio de la labor será honroso y se tendrá por oficio de nobles, como lo es; [...] no sean alcaldes ni regidores, sin haber sido soldados o ser labradores. ([1607]1994: 154-155).

Para ello el acceso a la tierra era fundamental, de modo que Valencia defendía la reducción de las grandes explotaciones con terrenos incultos y la concesión de estos últimos a pequeños agricultores desposeídos, los cuales estarían obligados a labrarlas al igual que el resto de propietarios:

si algunos lugares tuvieren dehesas de pasto cualesquiera en mayor cantidad que las que bastarían para los que tienen derecho de pastar en ellas, rómpanse en la cantidad sobrada y en la parte más cómoda para la labor, viñas, olivares o huertas, teniendo consideración que no se perjudique al todo del pasto del reino. Si señores, caballeros, mayorazgos y hombres ricos tienen también dehesas o montes, cuyos pastos sobren sin el dicho perjuicio, también se rompan. Así, éstas de señores, como las realengas y las de los concejos y cualesquiera tierras de las que se han de cultivar o se cultivan ahora, que se posean por concejos o particulares en mayor cantidad de la que se les ha de permitir a un hombre,

2 Gutiérrez de los Ríos, Gaspar. 1600. Noticia general para la estimación de las artes y de la manera en que se conocen las liberales de las que son mecánicas y serviles: con una exhortación a la honra de la virtud y del trabajo contra los ociosos y otras particulares para las personas de todos estados. Madrid: Pedro Madrigal.

Valencia, Pedro de. [1607] 1994. Discurso sobre el acrecentamiento de la labor de la tierra. En Gaspar Morocho Gayo (dir.) Pedro de Valencia. Obras Completas. Vol. IV/1. Escritos sociales I. Escritos económicos. León: Universidad de León, pp. 137-158. 
repartidas en suertes se han de dar a censo perpetuo a los vecinos, con una pensión muy moderada, de manera que les esté bien labrarlas a los labradores. Y esto también les será más conveniente a los dueños, concejos, mayorazgos y particulares, porque les valdrá más tener renta cierta y perpetua en pequeña cantidad, que incierta y desigual en mayor, además de que a la pública utilidad se debe posponer cualquier interés particular. ([1607]1994: 150)

Este arbitrista trataba de facilitar el acceso de los campesinos a la tierra, pero como se observa en el texto anteriormente señalado, no proponía en ningún caso un cambio radical en el régimen señorial, sino compatibilizar éste con la posibilidad de que los agricultores dispusieran de parcelas para explotar en régimen de enfiteusis.

Igualmente, en la misma línea que Gutiérrez de los Ríos, Pedro de Valencia se mostró contrario a la ociosidad y escribió una obra al respecto $^{4}$ donde condenaba duramente la inactividad y la identificaba como una causa nociva para la estabilidad y abastecimiento del estado:

es el ocio la misma destrucción de la república, porque las artes y oficios y el trabajo han de juntar y adquirir los mantenimientos y vestidos y las demás cosas necesarias a la vida, y todas faltan en huyendo cada uno del trabajo y espera[ndo] que otro haga y trabaje para él. ([1608] 1994, 160)

Otro arbitrista destacable es Lope de Deza (1546-1625) quien realizó en su arbitrio una apología de la agricultura ${ }^{5}$. Este pensador observaba con preocupación la desfavorable situación en la que se encontraba el trabajo en el agro y señaló el que, según su perspectiva, era el principal motivo de esta circunstancia: causa del desamparo y poca estimación de la agricultura es no estar privilegiada como merece su excesivo trabajo, necesidad inexcusable y universal utilidad, siendo fuerza que hay de tener algunas exenciones y recompensas para que no solo no la desamparen, sino para que la sigan y se le aficionen. (1618: 38v.).

Asimismo, llegó a identificar hasta una decena de factores que perjudicaban al trabajo agrario tales como la emigración, el abandono de los campos, la dedicación a oficios improductivos, la elevada presión fiscal a la que estaban sometidos los labradores o la falta de conocimientos técnicos adecuados. Sin embargo, como advirtió García Sanz (1992: 21), Deza empleó una treintena de hojas a estudiar cómo la falta de privilegios de los agricultores afectaba negativamente al trabajo en el campo, mientras que en otras cuestiones el arbitrista no había superado la docena de páginas. Así pues, ello revela la especial intención de Deza por dar a conocer las condiciones y circunstancias en las que se encontraba los labradores y su propuesta para que a estos trabajadores se le concedieran algunos privilegios:

En la octava causa de la carestía de los frutos y falta de labradores, que era no estar suficientemente privilegiada la agricultura y sus ministros, conviene, $[\ldots]$ cumplirles sus privilegios y dárselos en forma que lo sean y tengan efecto, sin que queden mancos y frustratorios. $(1618,190)$

Deza fue muy crítico con la Pragmática sancionada por Felipe II en $1594^{6}$, pues consideraba que las concesiones de Felipe II a los agricultores era insuficientes, de modo que proponía ampliarlas:

\footnotetext{
Valencia, Pedro de. [1608] 1994. Discurso contra la ociosidad. En Gaspar Morocho Gayo (dir.) Pedro de Valencia. Obras Completas. Vol. IV/1. Escritos sociales I. Escritos económicos. León: Universidad de León, pp. 159-173. Deza, Lope de. 1618. Gobierno político de agricultura. Madrid: Viuda de Alonso Martín de Balboa.

"Ley XV, D. Felipe II en Madrid, año 1594, a 9 de marzo. No se haga ejecución en las bestias de arar, aperos de labor, sembrados y barbechos de los labradores, sino en los casos y modo que se expresan. Mandamos que los labradores que por sus personas o por sus criados y familia labraren, no puedan ser ejecutados por deuda debida por carta, contrato o en otra cualquier manera, en su bueyes, mulas, ni otras bestias de arar, ni en los aperos ni aparejos que tuvieren para labrar, ni en sus sembrados ni barbechos, en ningún tiempo del año, aunque no tengan otros bienes, salvo por los pechos y derecho a nos debidos o por las rentas de las tierras del señor de la heredad, o por lo que el tal señor les hubiere prestado y socorrido para la dicha labor, y en estos tres casos, cuando no tuvieren otros bienes de que puedan ser pagadas las dichas deudas y que en un par de bueyes, mulas u otras bestias de arar no puedan ser ejecutados en los dichos tres casos, ni por otro alguno. 2. Que las personas de los dichos labradores no puedan ser presos por deuda alguna, que no descienda de delito en los meses de julio y los siguientes hasta fin de diciembre; y que el juez o ejecutor que contraviniere, así a lo dispuesto en el capítulo primero como en este, sea suspendido de oficio por un año y el acreedor que lo pidiere por el mismo caso haya perdido y pierda la deuda y el labrador quede libre de ella". Ley 25, título 31, libro 11 . En Carlos IV de España (mandada formar por) [1805] 1992. Novísima Recopilación de las Leyes de España, tomo V, libros X, XI y XII. Madrid: Boletín Oficial del Estado, p. 293
} 
El primer privilegio que los labradores han de tener es no poder estar presos por deudas civiles en tiempo alguno de cualquier calidad y suerte que fuesen, en que se les hacían dos grandes bienes uno librarlos de la molestia y detención de la cárcel y desocuparlos para su labranza; otro, excusarlos de muchos empréstitos, censos, fiados y mohatras que toman, pues con esta exención poquísimos se las querrían dar, y antes se remediarían de su trabajo y diligencia vendiendo parte de su hacienda o cultivándola mejor que del dinero ajeno con que ellos y sus heredades se cautivan y pierden. El segundo privilegio es consecuencia del primero, que ha de ser la libertad de sus pares de labor sean cuales fueren y cuantos fueren, con todos sus aparejos e instrumentos rústicos, para que no puedan ser sacados ni molestados por prendas o ejecución de deuda alguna en ningún tiempo del año, ni asimismo los barbechos que tuvieran hechos para sus sementeras ni los sembrados antes de que se cojan estando pendientes en la misma heredad los frutos. El tercero, que de los montones y cosechas que tuvieren de pan no se les quite por ninguna deuda o acreedor lo que pareciere necesario para su siembra según la tierra que tuvieren cosechada, y lo que pareciere ser necesario para el sustento de aquel año, así de los labradores como de sus pares y yuntas, y lo mismo se entienda del vino, pudiendo ser ejecutados en lo que de esto sobrare y no en otra cosa alguna de los dichos frutos, y a quien le pareciere que esto es demasiado, quite lo que quisiere y verá que todo lo demás queda frustrado y sin efecto. (1618: 190-191)

Sin embargo, el arbitrio de Lope de Deza no fue tenido en cuenta, ya que, quince años después de la publicación de su arbitrio, la norma legislativa volvió a ser sancionada en 1633 por el rey Felipe IV, sin incluir ninguna modificación al texto elaborado en 1594.

Por su parte, Fray Benito de Peñalosa y Mondragón señalaba en su obra de $1629^{7}$ que ser honrados y reconocidos socialmente era una de las aspiraciones más importantes para los españoles. Sin embargo, como se señaló al estudiar a Gutiérrez de los Ríos, el trabajo agrícola era ignominioso y Peñalosa, consciente de ello, indicó en su arbitrio que esta circunstancia hacía que la sociedad rechazara la agricultura y buscase otras alternativas:
Considerando los españoles altivos y honrosos, cuan abatido es el oficio de labradores en España, por maravilla se inclinan a él, ni se precian descender de la antigüedad de ellos y si por la necesidad alguno se aplica, apenas lo fueron los padres cuando todos sus hijos o siguen las letras o las armas y si no aprenden algún oficio se van huyendo del trabajo de la cultura del campo, más costoso y menos honroso, a las Indias y otros reinos de esta monarquía. (1629: 175r-175v.)

El fraile arbitrista afirmaba también que la imagen que se difundía del campesino estaba distorsionada y a ello, según Peñalosa, había contribuido el teatro, pues en los escenarios se caricaturizaban y ridiculizaban las circunstancias y formas de vida de los agricultores:

El estado de los labradores en España en estos tiempos está el más pobre y acabado, miserable y abatido de todos los demás estados, que parece que todos ellos juntos se han aunado y conjurado a destruirlo y arruinarlo; y a tanto ha llegado que suena tan mal el nombre de labrador que es lo mismo que pechero, villano, grosero, malicioso y de ahí bajo, a quien solo adjudican las comidas groseras, los ajos, cebollas, las migas y cecina dura, la carne mortecina, el pan de cebada y centeno, las abarcas, los sayos jironados y caperuzas de bobo, los bastos cuellos y camisas de estopa, los zurrones y toscos pellicos y zamarros adobados con miera, las chozas y cabañas, las casas de tapias desmoronadas y caídas y algunas mal aderezadas tierras $\mathrm{y}$ algunos ganados flacos y siempre hambrientos por carecer de pastos comunes, afecto y cargado todo de tributos, hipotecas, pechas, censos y muchas imposiciones. Los menajes y ajuares de sus casas y bodas son de risa y entretenimiento a los cortesanos y estas comedias y entremeses de ahora los pintan y remedan haciéndoles aún más incapaces contrahaciendo sus toscas acciones por más risa del pueblo. (169r-169v.)

Ante esta situación, el fraile, al igual que los arbitristas señalados anteriormente, programó una serie de medidas para aumentar la aprobación social de la actividad agraria e incentivarla. Entre sus propuestas se encontraba la de conceder privilegios a los campesinos $\mathrm{y}$, aunque estos eran más simbólicos que los que 
señalaba Pedro de Valencia, eran también relevantes. Peñalosa insistía en que se concediese blasones a los campesinos, de este modo trataba de elevar la consideración social de los mismos al atribuirles elementos propios de individuos con una relativa preeminencia en la sociedad del siglo XVII:

Podía muy bien honrarse a los labradores pues se quedan en España en tanto beneficio suyo con blasón de esta excelencia que gozan los familiares y ministros del Santo Oficio de la Inquisición para que cuando vengan a las ciudades a los autos que hiciese el Santo Tribunal los honren y respeten y nazca emulación de otros para imitarlos y que viéndoles con tal insignia donde quiera les hagan reverencia y con las exenciones y privilegios que a tan honrados ministros se deben estarán muy defendidos y amparados. Título que les viene muy justo por su bondad y cristiandad que aún los romanos para llamar a un hombre de bien le nombraban buen labrador, donde tuvo origen en nuestra España llamar al estado de los labradores el de los hombres buenos. $(1629,173 \mathrm{r}-173 \mathrm{v}$.)

No obstante, este arbitrista también sostenía que lo esencial para alcanzar el reconocimiento social era disponer de un nivel de riqueza considerable. Así pues, abogaba por la adquisición de tierras de titularidad pública por el campesinado, mediante concesiones estatales como recompensa por sus servicios o a través de transacciones.

conviene que digamos como se les ha de socorrer y ayudar a los labradores porque hoy están muy acabados con suma desdicha y pobreza y cual sea la cantidad de hacienda del campo que por lo menos ha de tener cada uno para gozar del nombre y preeminencias de labrador para que tenga mayor lustre y riqueza para ejercitar su inclinación natural. De dos maneras se les puede socorrer a los labradores y la primera que se compren muchos campos, heredades y dehesas y ser repartan en suertes y caballerías y a unos se les vendan con plazos largos en precios cómodos sin intereses ni réditos y a otros se les haga mercedes de ellas por servicios. La segunda, presentándoseles dineros, por el tiempo y plazo que conviniere y aun dándoles alguna ayuda de costa si fueran solícitos y extrema- dos en el ejercicio y antigüedad de sus oficios. (1629: 176v.-177r.)

Asimismo, Peñalosa indicaba que se debía permitir la participación de los campesinos a la hora de resolver cuestiones relacionadas con el mundo agrario, pues estos disponían de amplios conocimientos sobre el medio rural:

serían bien que entre otros premios se les diese que no solo fuesen alcaldes de sus lugares, pero corregidores y gobernadores de sus partidos que, muchas veces en nuestra España, se celebró ese por un sano y atentado gobierno que, por lo menos, como tienen tanto estudio y experiencia de las labores y cosechas del campo, de los tratos y condiciones de ellos mismos, de las calidades de la tierra y cimas y temporales (que casi todos los pleitos de los labradores se originó de lo sobredicho), fácilmente, los podrán librar y determinar con la ciencia y arte de la agricultura que letrados de muchas leyes y sin la dicha experiencia más los ofusca y embaraza como es notorio. $(1629,174 \mathrm{r} .-174 \mathrm{v}$.)

Finalmente, Benito de Peñalosa consideraba, al igual que Gutiérrez de los Ríos, que la agricultura y la actividad militar eran asimilables, ya que ambas eran necesarias y, por tanto, defendía que la situación de los labradores fuera equiparable a la de los soldados:

Convendría para que este estado se realzase y por largos tiempos se ejercitase y aún perpetuase en las familias ofrecerles medras y honores a la proporción de los que por las armas se han conseguido pues es tan necesaria para todas las repúblicas la labranza. $(1629,175 \mathrm{v}$.)

Miguel Caxa de Leruela (c. 1565-1631) publicó en 1631 Restauración de la abundancia de España ${ }^{8}$ donde defendía a la ganadería, en especial la estante, como la principal actividad que se debía incentivar para la recuperación económica de España y criticaba a aquellos arbitristas que diferían de su opinión. Además, consideraba que el ganado era fundamental para el resto de sectores económicos:

Todos, empero, cuantos han escrito sobre el estado de las cosas de España y tratado de remediar la carestía general, han desbarrado; unos, 
por una parte, otros, por otra, sin haber atinado a la puerta única del socorro que es la crianza de los ganados. Pues, aunque concurren muchas causas, la principal de donde se origina es la falta de ganados, mayores y menores, señaladamente de los estantes, nervio substancial del utilísimo gremio de labradores, sobre quien se funda la pesadumbre de la máquina civil, cuya ruina se ha llevado tras sí la abundancia y arrastrado todo el comercio, encarecido todas las cosas y mucho más las inmediatas a su dependencia; carnes, lanas, corambres, bueyes, ovejas, cabras y las demás especies de ganado con el lacticinio y la numerosa multitud de cosas que incluye el lanificio. Y como todas las cosas, obras y portes alteran y regulan sus precios con el punto de los alimentos que es el contrabajo de la música y armonía civil de aquí se ha seguido la despoblación de los lugares, la necesidad común de los naturales y la intolerable carestía de precios. $(1631,45-46)$.

Efectivamente, este arbitrista indicaba que la agricultura dependía de la ganadería, ya que los animales eran imprescindibles para la labranza de las tierras, así como para la obtención de productos fundamentales en la vida del hombre: alimentos y vestido.

habemos de confesar la mucha parte que tienen en la vida y conservación del hombre [los ganados], pues sin ellos ninguno puede vivir [...] Ni se puede negar que tiene mucho menos de encarecimiento respecto del cuerpo civil decir que el ganado es fundamento que lo sustenta. Porque si faltara necesariamente había de faltar la labranza, no habiendo quien llevara el peso que lleva el buey. Y restara la naturaleza humana reducida a un legón o azada cultivando cada uno para sí solo y aún no bastara cuando la edad permaneciera robusta y la salud valiente. $\mathrm{Y}$ cuanto quiera que cesara de todo punto la labranza sin la ayuda del ganado y que nuestra vida careciera del principal sustento que es el pan. Fuera mayor inconveniente para la vida civil la falta del ganado respecto del vestido y de las demás comodidades, regalos y adornos que el ingenio humano (aventajándose a sí mismo) ha hallado en sus frutos y efectos para cubrir su desnudez porque requiere esta parte mayor comercio de tratos, contratos, obras, oficios y artificios que no la sementera, cosecha y labor del pan y de los frutos de la labranza y mayor tráfico e intervención de personas. (1631, 17 18).

No obstante, este arbitrista reconocía que el problema más acuciante de la ganadería estante era su desvinculación con respecto a la Mesta:

"Los ganados que llaman estantes son los que no salen afuera de sus suelos, jurisdicciones y pastos comunes, a herbajar de invernadero ni agostadero y estos no gozan de los privilegios concedidos a la Cabaña Real ni del favor de la comisión de los Alcaldes Mayores Entregadores. Puesto que gozaron de lo uno y de lo otro siempre, hasta el año 1604 que, a instancia del reino, fueron excluidos de estos favores y les obligaron a pedimento del Concejo de la Mesta a ser hermanos de él en tres casos penales $^{9}$. [...] Desde entonces quedaron los estantes destituidos de todo favor y amparo y en lugar de la hermandad antigua que tenían con los del Concejo de la Mesta sucedió la emulación ordinaria que tienen los profesores de un trato. (1631, 94-95).

Así las cosas, Caxa de Leruela demandaba que ganado estante no pudiera ser embargado o confiscado por el endeudamiento de sus propietarios:

privilegiar la cantidad de ganado mayor y menor que ha menester la agricultura para estar perfectamente instruida. Con tal exención y prerrogativa que no se pueda hacer ejecución ni prenda en ellos por deuda civil como están privilegiados los bueyes y mulas y los demás instrumentos aratorios. (1631, 248-249)

En definitiva, tras este breve recorrido por algunos de los autores más relevantes del arbitrismo agrarista, es posible conocer la consideración que se tenía de los campesinos en el siglo XVII. Así pues, teniendo en cuenta las medidas que se han subrayado en los arbitrios precedentes, se manifiesta la pésima concep-

Acudir a ellas [Mestas] con los ganados que tuvieren entre los suyos envueltos y perdidos para que llevándolos a la Mesta los dueños los reconozcan por su hierro y señal y si no parece dueño los haya el Concejo de la Mesta a quien pertenecen. [...] El segundo caso en que están obligados a guardar las leyes es manifestar al alcalde de cuadrilla más cercano que hubiere sus ganados enfermos, estando dolientes de viruelas, sanguiñuelo o gota para que le den y señalen tierra aparte donde anden porque no peguen la dolencia a otros. El tercero caso es guardar las leyes del título sexto de las de la Mesta sobre las posesiones que ganan y pierden los ganados en las dehesas [...] (Caxa de Leruela 1631, 210-211) 
ción que se tenía de este tipo particular de trabajadores. Efectivamente, la mentalidad de la época rechazaba los oficios manuales y por ello el del campesino estaba estigmatizado y era ridiculizado en las obras de teatro. Sin embargo, para los arbitristas agraristas las actividades del sector primario eran esenciales, pues las consideraban como la principal fuente de riqueza para España. Así pues, ante situación problemática, los pensadores que se han mencionado anteriormente no se limitaron a indicar medidas meramente de carácter económico, sino que apostaron por inducir un cambio en la mentalidad imperante de la época, de modo que se modificase el estatus del campesinado y se llegase a asimilar con el del estamento de los privilegiados o, al menos, con el de la nobleza. Por tanto, se evidencia la profunda influencia que la consideración social de un determinado trabajo podía tener a la hora de elegirlo o rechazarlo. Frente al trabajo manual, que era rehusado, se preferían las consideradas como profesiones liberales, ejercidas mayoritariamente por los miembros del grupo social de los privilegiados. En efecto, los esfuerzos de Gutiérrez de los Ríos iban en esta dirección, pues pretendía que el trabajo agrario se considerara liberal. Asimismo, se perseguía el "ennoblecimiento del campesino", pues entre las medidas que fueron señaladas más arriba se encontraban algunas de las características fundamentales que diferenciaban al estamento nobiliario del resto de la sociedad. Ejemplo de ello es el empleo de elementos simbólicos, como los blasones, o las exenciones fiscales y jurídicas entre las que se encontraba la imposibilidad de embargo de bienes por impagos tanto para labradores como ganaderos. Es, pues, manifiesto que lo que subyace en estas propuestas es un interés denodado por modificar el estatus del campesino. Por tanto, los arbitristas agraristas del siglo XVII propusieron en sus obras unos cambios que, de haberse producido, habría quebrantado el orden socioeconómico establecido en el Antiguo Régimen. Sin embargo, se trataba de proyectos utópicos y prácticamente irrealizables, pues, los destinatarios de los arbitrios, así como a quienes les correspondía implementarlos pertenecían, generalmente, al estamento de los privilegiados. Por tanto, es- tos, defensores de sus propios intereses, iban a presentar férreas reticencias y se iban a oponer a la promoción de modificaciones que les perjudicaran.

\section{Conclusiones}

En el siglo XVII, los arbitristas agraristas tuvieron un éxito muy limitado. Ya se ha indicado como las propuestas que estos pensadores publicaban no tenía un efecto real sobre la legislación ni sobre los gobernantes del momento. Asimismo, es destacable un caso paradigmático de este relativo fracaso: el arbitrio de Rojas Villandrando ${ }^{10}$. En él aparecen plagiadas las ideas de otros autores, lo cual, como supo ver acertadamente Gutiérrez Nieto (1986: 329332 ), indica que la difusión de los proyectos de los pensadores económicos de aquel tiempo era muy reducida, pues de lo contrario Rojas no hubiera podido apropiarse, impunemente, de las propuestas de otros. Sin embargo, el arbitrismo no fracasó absolutamente. En efecto, si se amplía la perspectiva es posible observar la existencia de medidas que recogen el espíritu de los arbitristas del siglo XVII en épocas posteriores. Una centuria más tarde, en el período de desarrollo de las ideas ilustradas, los proyectistas tomarán el relevo a los arbitristas. Perdices de Blas, especialista en esta temática, afirma que "los herederos de los arbitristas y los arbitrios son los proyectistas y los proyectos del siglo XVIII. La diferencia entre unos y otros es la mayor precisión de los segundos" (1996, 142). Efectivamente, en el Setecientos aparecen personajes como Pedro Rodríguez de Campomanes o Bernardo Ward quienes, influidos por el racionalismo de su tiempo, difundirán propuestas para mejorar la situación económica de España. Además, si en el siglo XVI los arbitristas rechazaban la ociosidad, en el período ilustrado, como estudió Pemán (1963), se perseguirá la inactividad en aras del desempeño de un trabajo productivo y se legislará en consecuencia ${ }^{11}$.

Por otra parte, en el siglo XIX se impulsaron procesos desamortizadores como el de Mendizábal (1836-1837) o el de Madoz (1854-1856). A través de estas medidas, se

10 Rojas Villandrando, Agustín de. 1611. El buen repúblico. Salamanca: Antonia Ramírez.

1 El título XXXI del libro XII de la Novísisma Recopilación de las Leyes de España lleva por título "De los vagos y modo de proceder a su recogimiento y destino", pp. 429-443. En esta sección aparecen dieciocho disposiciones legislativas, trece de ellas fueron promulgadas en el siglo XVIII y entre éstas últimas Carlos III, monarca ilustrado de España por antonomasia, sancionó una decena. 
pretendía de iure facilitar el acceso a la adquisición de tierras por parte de la población, algo que Pedro de Valencia había ya defendido doscientos años. Sin embargo, el efecto último que los arbitristas del siglo XVII perseguían no se logró en el Ochocientos. En esta última centuria se tomaron decisiones más radicales y se apostó por la expropiación, mientras que Valencia había apostado por un contrato enfitéutico. Sin embargo, las condiciones en las que se encontraba el campesinado no experimentaron cambios relevantes. Así las cosas, queda demostrado como el arbitrismo y más concretamente el agrarista ha tenido una relevancia destacada en la historia económica española.

\section{Fuentes y bibliografía}

Alvar Ezquerra, Alfredo. 1999. Alcuni dati e considerazioni sugli arbitristi italiani durante el regno di Filippo II. En Bruno Anatra e Francesco Manconi (a cura de) Sardegna, Spagna e Stati italiani nell'età di Filippo II. Atti del Convegno internazionale di studi storici nel IV centenario della norte di Filippo II. Cagliari: AM\&D Edizioni.

Avilés Fernández, Miguel; Villas Tinoco, Siro y Cremades Griñán, Carmen María. 1988. La crisis del siglo XVII bajo los últimos Austrias (1598-1700). En Ángel Montenegro Duque (coord.) Historia de España. T. 9. Madrid: Gredos.

Carlos IV de España (mandada formar por) [1805] 1992. Novísima Recopilación de las Leyes de España. Madrid: Boletín Oficial del Estado.

Caxa de Leruela, Miguel. 1631. Restauración de la abundancia de España o prestantísimo, único y fácil reparo de su carestía general. Nápoles: Lázaro Scorigio.

Cruz Yábar, María Teresa. 1996. Gaspar Gutiérrez de los Ríos, teórico de la estimación de las artes. Biografía. Academia: Boletín de la Real Academia de Bellas Artes de San Fernando. 82, pp. 401-460.

Cruz Yábar, María Teresa. 1997. Gaspar Gutiérrez de los Ríos, teórico de la estimación de las artes. II. Formación y obra. Academia: Boletín de la Real Academia de Bellas Artes de San Fernando. 84, pp. $383-422$

Deza, Lope de. 1618. Gobierno político de agricultura. Madrid: Viuda de Alonso Martín de Balboa.

Dubet, Anne y Sabatini, Gaetano. 2009. Arbitristas: Acción política y propuesta económica. Introducción. En José Martínez Millán y María Antonieta Visceglia (dirs.) La monarquía de Felipe III. La corte. Vol. III. Madrid; Fundación: Mapfre, pp. 867-936.

Echevarría Bacigalupe, Miguel Ángel. 1998. Flandes y la monarquía Hispánica. 1500-1713. Madrid: Sílex. García Fernández, Máximo. 2002. La economía española en los siglos XVI, XVII y XVIII. Madrid: Actas.

García Sanz, Ángel. 1992. Estudio preliminar. En Lope de Deza. Gobierno político de agricultura. Madrid: Instituto de Cooperación Iberoamericana; Sociedad Estatal Quinto Centenario; Instituto de Estudios Fiscales.

Gutiérrez de los Ríos, Gaspar. 1600. Noticia general para la estimación de las artes y de la manera en que se conocen las liberales de las que son mecánicas y serviles: con una exhortación a la honra de la virtud y del trabajo contra los ociosos y otras particulares para las personas de todos estados. Madrid: Pedro Madrigal

Gutiérrez Nieto, Juan Ignacio. 1986. El pensamiento económico, político y social de los arbitristas. En José María Jover Zamora (dir.) Historia de España Menéndez Pidal. El siglo del Quijote (1580-1680). Religión, filosofia, ciencia. Vol. XXVI (1). Madrid: Espasa Calpe, pp. 235-354.

Mousnier, Roland E. 1980. The Institutions of France under the Absolute Monarchy 1598-1789. The Organs of State and Society. Vol. II. Chicago and London: The University of Chicago Press.

Pemán, José María. 1963. La Ilustración y su impulso al trabajo en el siglo XVIII. Madrid: Cámara Oficial de la Industria de Madrid.

Peñalosa y Mondragón, Benito de. 1629. Libro de las cinco excelencias del español que despueblan a España para su mayor potencia y dilatación. Pamplona: Carlos de Labayen.

Perdices de Blas, Luis y Reeder, John. 2006. Arbitrismo y economía en el Quijote (1605-1615). En Luis Perdices de Blas y Manuel Santos Redondo (coords.) Economía y literatura. Madrid: Ecobook, pp. 35-75. 
Perdices de Blas, Luis y Sánchez Molledo, José María (eds.) 2007. Arbitrios sobre la economía aragonesa del siglo XVII. Zaragoza: Prensas Universitarias de Zaragoza, Instituto de Estudios Altoaragoneses, Instituto de Estudios Turolenses, Departamento de Educación, Cultura y Deporte del Gobierno de Aragón e Institución "Fernando el Católico".

Perdices de Blas, Luis. 1996. La economía política de la decadencia de Castilla en el siglo XVII. Investigaciones de los arbitristas sobre la naturaleza y causas de la riqueza de las naciones. Madrid: Síntesis.

Rojas Villandrando, Agustín de. 1611. El buen repúblico. Salamanca: Antonia Ramírez.

Sánchez Molledo, José María. 1997. El pensamiento arbitrista en el reino de Aragón en los siglos XVI y XVII. Madrid: Universidad Complutense de Madrid.

Sánchez Molledo, José María. 2005. Diccionario de arbitristas aragoneses de los siglos XVI y XVII. Zaragoza: Institución "Fernando el Católico".

Sánchez Molledo, José María. 2009. Arbitristas aragoneses de los siglos XVI y XVII. Textos. Zaragoza: Institución "Fernando el Católico".

Urí Martín, Manuel. 1998. Crisis y arbitrismo. Quevedo y el pensamiento económico español del Siglo de Oro. La Perinola. Revista de investigación quevediana, 2, pp. 263-302.

Valencia, Pedro de. [1607] 1994. Discurso sobre el acrecentamiento de la labor de la tierra. En Gaspar Morocho Gayo (dir.) Pedro de Valencia. Obras Completas. Vol. IV/1. Escritos sociales I. Escritos económicos. León: Universidad de León, pp. 137-158.

Valencia, Pedro de. [1608] 1994. Discurso contra la ociosidad. En Gaspar Morocho Gayo (dir.) Pedro de Valencia. Obras Completas. Vol. IV/1. Escritos sociales I. Escritos económicos. León: Universidad de León, pp. 159-173.

Vilar Berrogain Jean. 1973. Literatura y economía. La figura satírica del arbitrista en el Siglo de Oro. Madrid: Revista de Occidente. 